\title{
A conceptual cost comparison of alternative tailings disposal strategies in Western Australia
}

\author{
A Carneiro The University of Western Australia, Australia \\ AB Fourie The University of Western Australia, Australia
}

\begin{abstract}
Increasing regulatory and social demands are key driving forces behind operational changes taking place in mining. As tailings storage facilities (TSFs) come under scrutiny, operators are looking at alternative tailings management strategies. Integrated tailings management, including technical, economic, environmental, social, and risk aspects of the operation is urgently required. Current evaluation methodologies used to decide on the preferred method are limited, and have often poorly addressed the issue of realistic financial provisioning for the responsible disposal of tailings. The use of high-density tailings may be the best available option in many cases. However, it is often deemed undesirable because of economics - a conclusion that sometimes results from short-term profit-based assessments. Furthermore, there is a recognised lack of information on the costs of dewatering technologies to aid in tailings management decision-making.

This paper reports on an economic evaluation completed for comparing the lifecycle costs of disposing a typical non-acid generating gold tailings in the Goldfields of Western Australia. Conceptual TSF designs were developed and costed for managing the tailings as slurry, thickened, and filtered. Key elements driving the costs of disposal are highlighted and discussed. The concepts of the West Australian Mining Rehabilitation Fund (MRF) are introduced and considered in the estimates. In the context of increasing tailings management challenges, changes in the lifecycle costs over a range of possible future case scenarios are presented within the results to evaluate to what extent different TSF designs and closure strategies have on driving the costs of disposal in the long-term. The paper ends with a discussion addressing the long-standing challenges of financially quantifying the 'real' costs of surface tailings disposal. An appropriate comparison depends on the assessment of the accumulated costs resulting from a more holistic approach. This serves to enable decision makers to decide on the best practice for tailings disposal efficiency to ensure sound environmental and social performance.
\end{abstract}

Keywords: tailings management, cost comparison, tailings storage facility design, Mining Rehabilitation Fund

\section{Introduction}

Challenges to the management of tailings are increasing the pressure placed on the mining industry to become more sustainable. Tailings storage facilities (TSFs) are coming under increased scrutiny, especially in the wake of recent failures. In addition to the overwhelming economic loss incurred from a TSF failure, far more wide-reaching are its effects on driving public perception, increasing regulatory burden and government oversight. The mining industry is trying to respond to pressures for changes by looking at the benefits of alternative tailings management practices, and developing advanced methods to reduce risk and be more responsive to increasing environmental and social concerns. Driving the interest in alternative strategies for the disposal of tailings is the need to lower the catastrophic environmental and public impacts from TSF failures, reduce water usage, and address the interest of stakeholders in the closure and long-term performance of areas disturbed by mining operations.

Integrated tailings management, including technical, economic, environmental, social, and risk aspects of the operation is being promoted as a potential solution to satisfy the escalating demands facing the mining community. However, review on the current evaluation methodologies used to decide on the preferred tailings management option has revealed that they are limited, and have often poorly addressed the issue of realistic financial provisioning for the responsible disposal of tailings. Though several studies cover 
comparative economic evaluation of tailings disposal methods (e.g. Fitton \& Roshdieh 2013; Johnson et al. 2013), review of publically available feasibility projects and conference papers has shown that they mainly account for capital and operational expenditures only, and just for certain items that are specific to a project. Generally, the arguments in favour of the selected tailings storage option have been dominated by achieving operational simplicity, and the goal of financial performance, by lowering capital and operating costs. However, low-capital alternatives may in fact not have significant, or any, cost advantage at all if associated potential environmental, social and risk costs are not recognised. These factors are difficult to incorporate in cost estimates, but may impose significant expenses and impediments to a project.

Compounding the difficulty to incorporate integrated management when evaluating tailings disposal options is the recognised lack of economic data showing that it is economically effective to manage a TSF considering all the potential costs over the entire lifecycle of the facility. The Mine Environment Neutral Drainage (MEND) program in Canada has recently released a report entitled 'Study of Tailings Management Technologies' outlining this issue (Klohn Crippen Berger 2017). The study was undertaken to examine and compare alternative methods for the management of tailings currently used in Canada and other jurisdictions with similar climatic conditions. Among the identified knowledge gaps is the lack of publically available information on the lifecycle cost of tailings management. The report also recommends further studies regarding the uncertainty associated with estimating rehabilitation costs. At the planning stage of a project's development, the closure plan is not comprehensively understood. Furthermore, closure requirements can change over the life of the mine (LOM).

In addition to the shortcomings associated with the currently used approaches for the evaluation of alternatives, and to the limited information on costs of dewatering technologies available in the public domain to aid in tailings management decision-making, the drawbacks of discounting procedures used in economic evaluations represent serious challenges to the selection of a sound tailings management strategy. In many cases, high-density tailings may be the best available option. However, using thickened tailings is commonly deemed undesirable because of economics, a conclusion that sometimes results from short-term profit-based valuations. The time value of money increases the pressure on private enterprise to maximise profits in the short-term. Therefore, as dewatered tailings disposal methods require additional initial capital expenditure, they are often disfavoured due to the continued managerial emphasis on deferring expenditure, promoting low-capital tailings disposal solutions with little emphasis on rehabilitation costs.

Closure requirements can change over the LOM, as can the best available technology for rehabilitation, stakeholder's expectations, and thus the costs of closure. Espinoza and Morris (2016) have presented a discussion about the differences in perspectives, goals, time horizons, and level of influence each stakeholder has over the project development (Figure 1). For instance, shareholders are interested in year-on-year profitability, elected officials may favour mining activities that provide the largest royalties during their administration, and the private sector's main interest is to maximise their returns during the project lease period. Consequently, accommodating stakeholders' misaligned aspirations contributes to the ever-increasing challenges to decide on a sound strategy for the disposal of tailings. 


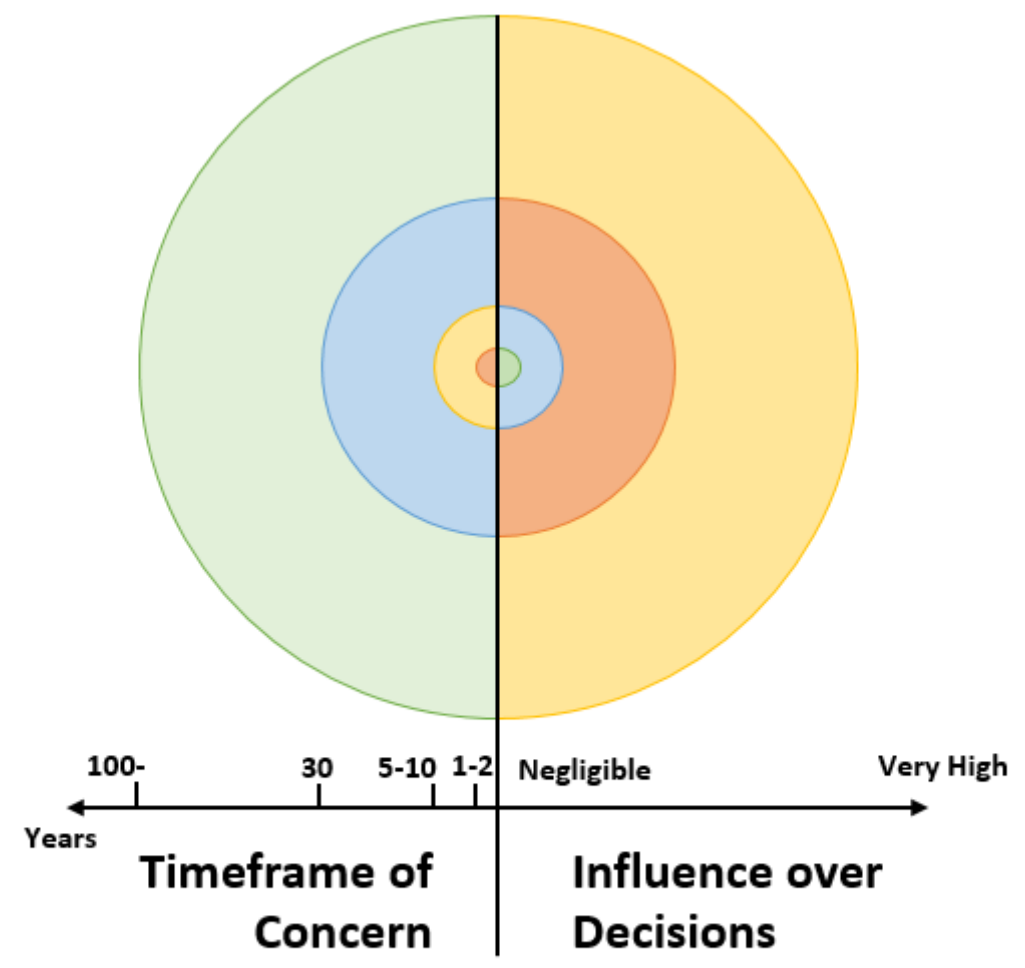

Society (future generations)

Community (current generation)
Politicians, Developers, Investors

Shareholders

Figure 1 Misaligned project development horizons of mining stakeholders (after Espinoza \& Morris 2016)

This paper reports on a case study for the disposal of a typical non-acid generating gold tailings stream in the Goldfields of Western Australia (WA). It focuses on tailings facility types and dewatering technologies, and presents a completed economic evaluation comparing the lifecycle costs of disposing the tailings as slurry, thickened, and filtered. A conceptual TSF design with associated equipment configuration and required infrastructure was developed for each option. Capital, operating, and closure cost estimates were prepared based on the designs. The concepts of the Mining Rehabilitation Fund (MRF) in WA are introduced and considered in the estimates. Key elements driving the costs of disposal are highlighted and discussed. Based on the increasing challenges to the management of tailings, changes in the lifecycle costs over a range of possible future case scenarios are presented within the results to evaluate to what extent different TSF designs and closure strategies have on driving the costs of disposal in the long-term. The paper concludes with a discussion about the importance of considering the totality of environmental, social, risk, and economic costs in the evaluation of tailings disposal methods for selecting the most cost-effective option.

\section{Economic evaluation of alternative methods of disposing tailings}

For the purpose of this paper, three tailings management strategies were selected for disposing a hypothetical, yet typical gold tailings stream in WA. Different types of dewatered tailings are stored in different types of facilities, with different associated infrastructure, equipment configuration, and operational criteria, and involve different closure strategies. The approach applied to this study focuses on the economic evaluation of the alternatives comparing dewatering technologies aiming at identifying key elements driving the costs of each option. The methodology used comprises the definition of tailings physical characteristics as well as operating parameters, design considerations, cost estimation, and analysis of the results. 


\subsection{Tailings physical characteristics and operating parameters definition}

The assumed tailings physical characteristics and operating parameters are similar to gold mine operations in WA. Based on publicly available data, and with the purpose of making this study easily transferable to other similar operations, reasonable characteristics were defined for a hypothetical tailings stream. Tailings are assumed to be from gold ore, processed in a mineral processing plant comprising crushing, grinding, flotation, thickening, and carbon-in-leach circuits. Among other relevant characteristics that affect the sizing of thickeners, filters, pumps and pipelines, the particle size distribution was assumed to be $75-80 \%$ less than $75 \mu \mathrm{m}$, and the specific gravity of tailings solids to be 2.79 . Operating parameters were based on an annual tailings production rate of $2 \mathrm{M}$ dry tonnes, resulting in a total of $30 \mathrm{M}$ dry tonnes of tailings solids to be disposed of over the 15 year operating LOM.

The proposed location for the TSF is in a semi-arid region, characterised by relatively low rainfall and high evaporation, thus the site water balance is negative. The selected site for building the facility is assumed to be flat topographically, and located $1 \mathrm{~km}$ away from where the tailings are produced.

Make-up water required for mineral processing will be sourced from a catchment point located $5 \mathrm{~km}$ from the plant. For the purpose of this study, it is considered that the plant will not vary the volume of tailings produced per year, and that the physical and geochemical characteristics of the tailings will remain unchanged over the LOM.

\subsection{Tailings storage facilities design considerations}

Design considerations were determined based on intensive literature review, discussions with experienced people in the industry and in the government, field trips to a tailings dam in a gold mining operation, and to a filtration plant, both located in WA, and feedback received on a previous cost estimate published in a past tailings conference proceedings (Carneiro \& Fourie 2017).

Access to reports detailing final design and construction considerations of existing TSFs in WA ultimately supported the selection of design parameters. Conceptual TSF designs along with associated infrastructure and equipment configuration were developed, considering assumed operational details and storage requirements for the project. The designs considered three surface disposal methods, differentiable by the degree of dewatering applied to the tailings slurry at the processing plant, before transport and disposal. The three options considered were conventional slurry at a solids content of $55 \%$ by mass, thickened tailings at a solids content of $65 \%$ by mass, and filtered tailings at a solids content of $80 \%$ by mass (moisture content (geotechnical) of $25 \%$, where moisture content is defined as weight of water as a percentage of the dry weight of solids).

\subsubsection{Design criteria and TSF geometry}

Different TSF geometries were designed for each alternative method depending on the consistency of the tailings given by the dewatering technology used upstream. Generally, conventional slurry tailings that are hydraulically discharged must be contained by perimeter embankments when the land is flat. Thickened tailings are considered to be non-segregating slurry able to form a deposit with beach slopes in the order of 1-3\%. In flat terrain, thickened tailings can be discharged to form a self-supporting cone with smaller perimeter embankments for its containment. Filtered tailings is stored by hauling, spreading and compacting the tailings in a dry stack as tailings is dewatered such that they are partially saturated as a moist soil.

In this specific case study, for the containment of the slurry tailings, the TSF designed is a paddock-type dam comprised of one square cell covering a footprint of 94 ha. Tailings will be discharged by spigotting from a ring dyke. The total design storage is $21.5 \mathrm{M} \mathrm{m}^{3}$ based on an assumed dry density of consolidated tailings of $1.4 \mathrm{t} / \mathrm{m}^{3}$. In its final profile, the tailings dam will be $30 \mathrm{~m}$ high.

For the thickened tailings option, the TSF is a circular-shaped paddock-type facility covering a footprint of 324 ha. Tailings will be discharged into the TSF using the central thickened discharge (CTD) method forming a cone with a $1,000 \mathrm{~m}$ radius. Based on an assumed average tailings beach angle of $2 \%$, in its final profile the 
cone will be $20 \mathrm{~m}$ high. Tailings deposition will occur by radial discharge from eight spigots located within the central area of the facility. The total design storage is $20 \mathrm{M} \mathrm{m}^{3}$ based on an assumed dry density of consolidated tailings of $1.5 \mathrm{t} / \mathrm{m}^{3}$.

For the filtered tailings option, the TSF is a dry stack-type deposit with the shape of a frustum of a pyramid with a rectangular base, covering a footprint of 48 ha. There will be no need for the construction of an embankment for tailings containment, as the assumed inherent strength of the facility will be derived from the placement and compaction of the tailings material itself. Slurry tailings will be pressure filtered to a 'dry' cake suitable to be loaded on trucks, hauled to the TSF, dumped, spread, and compacted to form a stable dry stack with $1 \mathrm{~V}: 4 \mathrm{H}$ side slopes. The total design storage is $16.2 \mathrm{M} \mathrm{m}^{3}$ based on an assumed dry density of consolidated tailings of $1.85 \mathrm{t} / \mathrm{m}^{3}$. In its final profile, the dry stack will be $60 \mathrm{~m}$ high.

\subsubsection{Tailings processing, transport and deposition}

Due to the varying degrees of dewatering applied to the tailings at the processing plant for each alternative, different tailings transport systems are considered for each option. Slurry tailings will be thickened in a high-rate thickener to about $55 \%$ solids, using a flocculant dosage of $30 \mathrm{~g} / \mathrm{t}$. Then, it will be pumped to the TSF by one of two pump trains, arranged in a duty/standby configuration, with each pump train consisting of five centrifugal pumps in series. Tailings will be transported via a $200 \mathrm{~mm}$ diameter high-density polyethylene (HDPE) pipeline and deposited sub-aerially from a slurry ring, located on the perimeter wall. A series of discharge points along the embankment will be used to dispose the slurry into conductor pipes to deliver tailings to the beach level.

During the operating life of the facility, TSF capacity will be increased by raising the embankment using the upstream method of construction, at a rate of $2 \mathrm{~m}$ per year. The coarser fraction of the tailings sourced from the adjacent tailings beach will be used as construction material. The decant road will also be raised at a rate of $2 \mathrm{~m}$ per year using harvested tailings, but following the concepts of the centreline method of construction.

Thickened tailings, at a solids content of $65 \%$, will be produced in a high-compression thickener, using a flocculant dosage of $30 \mathrm{~g} / \mathrm{t}$. The tailings will be pumped to the TSF by a piston-diaphragm positive displacement pump coupled to two charge pumps arranged in a duty/standby configuration. Tailings will be transported in a $200 \mathrm{~mm}$ diameter HDPE pipeline and deposited sub-aerially from the spigots connected to the end of the tailings distribution pipeline. TSF capacity will be increased by raising the spine access way, and consequently the tailings deposition point, using the centreline method of construction. Tailings sourced from the adjacent tailings beach will be used as construction material. As thickened tailings are assumed to be deposited by radial discharge, forming a self-supporting cone of gentle slope angle, the frequency of raising the deposition point does not follow a constant rate. In the first years of operation, the height of the tailings cone will increase rapidly, reducing the rate of rise as the layer of tailings is expected to cover larger surface areas in the following years. Thus, the raising of the spine access way is planned to follow the rate of rise of the cone. Raises of $2 \mathrm{~m}$ are intended, but not at regular time intervals.

Filtered tailings will be produced by three fast-opening filter press units comprised of 60 chambers resulting in $595 \mathrm{~m}^{2}$ of filtration area each. The slurry will be delivered to a filtration plant capable of producing filter cake at the solids content of $80 \%$. The plant includes three filter hydraulic units, three slurry feed pumps, one cake pressing compressor, three dry air compressors, two manifold flush pumps, two cloth wash pumps, three filtrate pumps, three cake conveyors for cake discharge, and one slurry tank agitator. Filter cake will be discharged onto conveyors beneath the filters. The filter cloths will be washed every cycle to ensure cloth and plate sealing surfaces are free of solids before commencing the next filtration cycle. From the cake conveyor, filter cake will be deposited into piles from which it is placed into trucks for delivery to the tailings facility. There, a dozer will spread the material, and a compactor will compact the tailings to form the dry stack. During the operating life of the facility, progressive reclamation of the TSF side slopes will happen on completion of each $20 \mathrm{~m}$ lift. 


\subsubsection{Major infrastructure requirement}

For the three TSFs, major infrastructure components common to all three include the construction of a TSF access ramp, access road from the plant to the TSF, pipeline corridors, and a topsoil stockpile. However, due to the difference in the water content of the tailings, and the disposal method to be applied, designs differ in infrastructure required for tailings transport and containment, water management, and seepage control.

For the TSF designed for slurry tailings, major infrastructure components include a starter embankment, and the underdrainage and decant systems. A $6 \mathrm{~m}$ high earthfill dam was designed with outer slopes at $1 \mathrm{~V}: 3 \mathrm{H}$ $\left(18^{\circ}\right)$ to facilitate contour ripping and the establishment of vegetation on the side slopes at closure. Proposed infrastructure designed for seepage control includes the construction of an underdrainage system consisting of collector drains and an underdrainage tower.

The design also considered the construction of a decant system to remove supernatant as well as storm water from the surface of the facility. The decant structure comprises an $8 \mathrm{~m}$ wide decant road that gives access to the centre of the TSF where underdrainage and decant towers are to be located. The suggested decant tower is constructed of vertically stacked, $1.8 \mathrm{~m}$ diameter slotted reinforced concrete pipe sections, while the underdrainage tower is built with $0.9 \mathrm{~m}$ diameter solid concrete pipe sections. Designs consider both structures resting on reinforced concrete slabs, and surrounded by an external zone of rockfill to retard the inflow of sediment into the towers. From there, decant water will be returned to the mill for re-use in the process via a $200 \mathrm{~mm}$ diameter HDPE pipeline. Make-up water needed for mineral processing will be pumped from a natural source via a $180 \mathrm{~mm}$ diameter HDPE pipeline.

For the TSF designed for thickened tailings, major infrastructure components include an environmental embankment, a spine access way, and two ponds for water management. A $2 \mathrm{~m}$ high earthfill dam, and an $8 \mathrm{~m}$ high $\times 8 \mathrm{~m}$ wide $\times 920 \mathrm{~m}$ long spine access way to the discharge point were designed with outer slopes at $1 \mathrm{~V}: 3 \mathrm{H}\left(18^{\circ}\right)$. As thickened tailings can be considered as a dense, non-segregating slurry, the TSF was designed as a passive system in regard to seepage control. Thus, no underdrainage system was designed to intercept seepage or consolidation water. Moreover, as the tailings are planned to be discharged in thin layers, evaporation is expected to occur fast enough to prevent bleed water.

Proposed infrastructure designed for storm water management includes the construction of a shallow pond designed to accommodate a one in 100 year, $72 \mathrm{hr}$ rainfall event, considered as $174 \mathrm{~mm}$ for the site in question. Surface water management includes the construction of a geomembrane-lined pond with dimensions similar to a CTD operation in the Goldfields of WA. In the wet season, considered as six months per year for this assumed site location, precipitation runoff collected in the pond will be returned to the mill for re-use via a $225 \mathrm{~mm}$ diameter HDPE pipeline. In the other six months, make-up water needed for mineral processing will be pumped from a natural source via a $225 \mathrm{~mm}$ diameter HDPE pipeline.

For the dry stack designed for filtered tailings, major infrastructure components considered the construction of two ponds for surface water management. The ponds were designed similar to the ponds for the thickened tailings option, but with dimensions proportional to the surface area of the dry stack that is significantly smaller. Precipitation runoff collected in the lined pond in the wet season will be returned to the mill for re-use via a $160 \mathrm{~mm}$ diameter HDPE pipeline. For the other six months of the year, make-up water needed for mineral processing will be pumped from a natural source via a $160 \mathrm{~mm}$ diameter HDPE pipeline.

\subsubsection{TSF closure strategy}

Proposed rehabilitation activities for each designed TSF are based on the review of mine closure plans of existing gold mining operations in the Goldfields of WA, regulations and guidelines, and discussions with consultants and people in the government. Different approaches for closure, and different lifecycles considered for discounting the rehabilitation costs were considered depending on the consistency of the stored tailings. For all the options, the proposed life of the project comprises the acquisition of equipment at year 0 , followed by two years of construction, and 15 years of mining operation. However, the LOM of each option is different because of the timeframe considered for TSF closure and rehabilitation. 
For the slurry TSF design, as tailings deposition ceases, the facility will be left drying for a period of three years so the surface of the TSF will be trafficable for construction equipment to perform rehabilitation work. This involves hauling and placing a layer of hard rock on the top and side slopes of the TSF, capping with topsoil, and deep ripping and spreading of seeds for the revegetation of all disturbed areas. After an assumed three years for regulator approval of the rehabilitation strategies, another 10 years of post-closure environmental monitoring to meet closure criteria and completion of the project's LOM were assumed. The assumption is thus that it will take 34 years from the start of the project to final relinquishment.

For the thickened tailings TSF design, rehabilitation activities will take place in the year after tailings deposition ceases, mainly consisting of hauling and placing topsoil to cap the TSF, hauling and placing hard rock to fill the ponds, and deep ripping and spreading of seeds for the revegetation of all disturbed areas. This will be followed by one year for regulator approval, and a further 10 years of post-closure environmental monitoring to meet closure criteria and completion of the project's LOM. The assumption is thus that it will take 29 years from the start of the project to final relinquishment.

For the dry stack design, reclamation will be undertaken concurrent to operations (i.e. once a lift of $20 \mathrm{~m}$ has been completed, its side slopes can be capped with topsoil and revegetated). Progressive rehabilitation is planned for years 8 and 13. Remaining reclamation will take place in the following year after tailings deposition ceases, mainly consisting of covering disturbed areas with topsoil and revegetating, and hauling and placing hard rock to fill the ponds. This will be followed by one year for regulator approval, and a further 10 years of post-closure environmental monitoring to meet closure criteria and completion of the project's LOM. The assumption is thus that it will take 29 years from the start of the project to final relinquishment.

\subsection{The cost estimates}

The database of costs used for evaluating the tailings disposal strategies has been developed mainly based on obtained third-party contract rates, in Australian dollars. It reflects current market pricing in WA. The net present cost (NPC) analysis for this study assumed a discounted cash flow (10\%) over the LOM. For comparison purposes, the cost estimates considered the main associated capital, operating, and closure costs to reflect the difference between the alternatives. They are not representative of all the costs to produce and store the tailings.

The capital expenditures (CAPEX) were estimated based on fixed, one-time expenses to be incurred on the purchase and installation of equipment, and on the construction of infrastructure required prior to the commencement of operations. For all the options, earthworks comprise site preparation (e.g. topsoil stripping from the TSF footprint area), and the construction of pipeline corridors and an access road from the plant to the TSF. Earthworks differ for building the perimeter embankment for the slurry and thickened tailings options, constructing the underdrainage and decant systems just for the slurry option, for building the tailings deposition system (e.g. spine access way) for the thickened tailings alternative, and ponds for surface water management for both thickened and filtered tailings options. Table 1 summarises the major cost items considered in the capital cost estimates. 
Table 1 Major cost items considered in the capital cost estimates

\begin{tabular}{|c|c|c|c|c|}
\hline \multirow{2}{*}{\multicolumn{2}{|c|}{ Major cost items }} & \multicolumn{3}{|l|}{ Tailings type } \\
\hline & & Conventional slurry & Thickened tailings & Filtered tailings \\
\hline \multirow{8}{*}{ Capital } & \multirow{4}{*}{$\begin{array}{l}\text { Tailings } \\
\text { handling }\end{array}$} & High-rate thickener & High-compression thickener & \multirow{4}{*}{ Filtration plant } \\
\hline & & Centrifugal pumps & Positive displacement pump & \\
\hline & & Tailings pipeline & Tailings pipeline & \\
\hline & & $\begin{array}{l}\text { Piping for spigot tees } \\
\text { and droppers }\end{array}$ & Spigot offtakes & \\
\hline & \multirow{4}{*}{$\begin{array}{l}\text { Other } \\
\text { capital }\end{array}$} & Site preparation & Site preparation & Site preparation \\
\hline & & Starter embankment & Embankment & - \\
\hline & & $\begin{array}{l}\text { Underdrainage and } \\
\text { decant systems }\end{array}$ & $\begin{array}{l}\text { Ponds for water } \\
\text { management }\end{array}$ & $\begin{array}{l}\text { Ponds for water } \\
\text { management }\end{array}$ \\
\hline & & $\begin{array}{l}\text { Make-up and return } \\
\text { water pumps and } \\
\text { pipeline }\end{array}$ & $\begin{array}{l}\text { Make-up and return water } \\
\text { pumps and pipeline }\end{array}$ & $\begin{array}{l}\text { Make-up and return } \\
\text { water pumps and } \\
\text { pipeline }\end{array}$ \\
\hline
\end{tabular}

For all the options, the operational expenditures (OPEX) have been estimated based on annual costs for pumping return and make-up water, and for paying the MRF levy. However, due to the use of different dewatering technologies, OPEX differs among the alternatives. For the slurry and thickened tailings options, OPEX involve annual costs for thickening tailings (e.g. adding flocculants and thickener energy), pumping tailings to the TSF, and increasing TSF capacity. OPEX for the filtered tailings option involves expenses with spare and wearing parts of the filtration plant, relatively high power consumption, and filter cake transport, spread and compaction by earthmoving equipment. For the purpose of this case study, as they were assumed to be similar, annual maintenance, labour, and general and administrative costs were not accounted for in the estimates. Table 2 summarises the major cost items considered in the operating cost estimates.

Table 2 Major cost items considered in the operating cost estimates

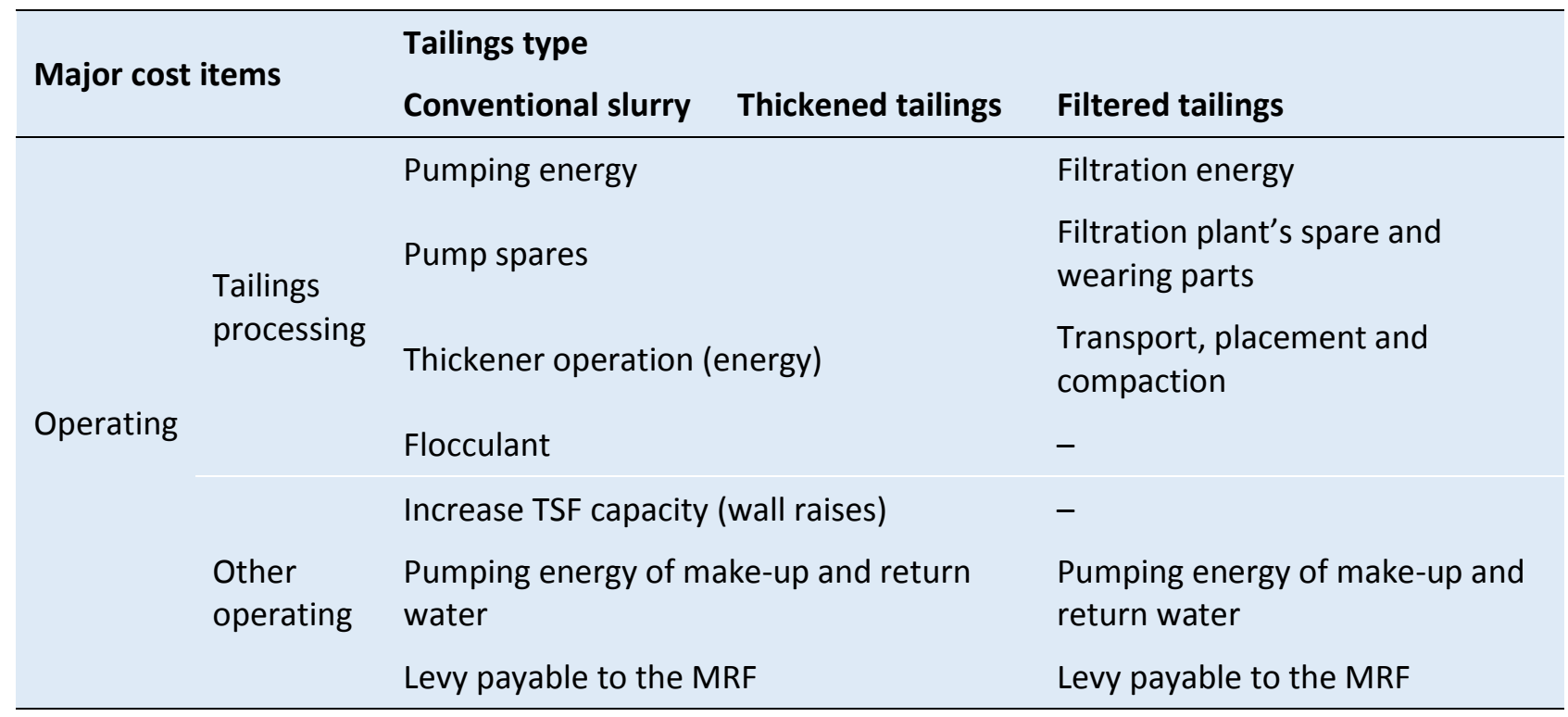

As this case study involves the disposal of tailings in WA, the levy payable to the MRF is included in the analysis. Mining companies in WA are required to make annual contributions to the MRF. The amount payable is based on the type of disturbance, in accordance with the rehabilitation liability categories. 
Each disturbance type is related to the description of infrastructure or land, and corresponds to a category with an associated unit cost rate as specified in the MRF regulations. The area in hectares covered by each disturbance type is then used to calculate the rehabilitation liability estimate (RLE). The RLE is calculated by multiplying the size of each disturbance type by the associated unit rate. For instance, an area disturbed by a TSF class 1 (characterised by its highest embankment being at least $5 \mathrm{~m}$ high), falls into category ' $A$ ', with an associated unit rate of AUD 50,000 per hectare. The amount of levy payable is assessed as the RLE multiplied by the current fund contribution rate (FCR) of $1 \%$.

The closure and rehabilitation expenditures were estimated differently for the alternatives. The closure costs for the slurry and thickened tailings options are based on one-time expenses to be incurred on rehabilitation works, and on annual costs of post-closure environmental monitoring. However, for the filtered tailings option, it was considered that progressive rehabilitation will take place throughout the LOM every time a $20 \mathrm{~m}$ lift is completed. So, at the time of closure, the remaining tailings reclamation will be undertaken, followed by annual costs of post-closure environmental monitoring. General management costs, and costs associated with demobilisation of plant and equipment were assumed to be similar for all the options, and were not accounted for in the estimates.

A literature review enabled development of the costing database. Despite the lack of publicly available data on tailings costs, some information was easily accessed. The 'Cost Estimation Handbook' (The Australasian Institute of Mining and Metallurgy 2012) offers cost indicators for various unit rates. In addition, ready data on TSF closure costs can be found in the Rehabilitation Cost Estimation Tool (RCE Tool) (State of New South Wales and Department of Planning and Environment 2017), and the Mining Financial Assurance Calculator (Business Queensland 2017).

\subsection{Assumptions}

The cost estimates focused on the physical structure required to store the tailings and did not consider stability issues. Regarding relevant inclusion and exclusion of costs, as the Goldfields region's groundwater is hypersaline and of little economic value, the cost of make-up water is just the operating cost of pumping it from a catchment point to the plant. Moreover, supply of construction material was not accounted for in the estimates. Although different volumes would be needed for each TSF, thus affecting the cost of each option, it is assumed that sufficient quantity will be available onsite. In addition, in spite of the recognised importance of seepage interception systems for preventing the naturally saline groundwater rising into the potential root zone of vegetation, closure cost estimates did not consider the construction of dewatering bores and trenches for managing groundwater levels after TSF rehabilitation.

Not all unit rates could be determined. For example, the unit rate for using tailings to annually increase TSF capacity was not obtained. However, the cost to win, load, haul, spread, moisture condition, and compact low-permeability fill for constructing the starter embankment was known. The same rate for construction using tailings was thus used. Although the cost of harvesting tailings from the beach and compacting it in the walls may be cheaper because of the shorter distance for hauling, it was assumed this rate is inclusive of the ongoing relocation of the piping required to accommodate the raised embankment.

For this specific case study, costs for the supply and installation of the filtration plant, and for the transportation of filtered tailings by truck, spreading by dozer, and compaction by compactor were found to be significantly variable. Therefore, different costs were assumed for the filtration plant, and for the placement of filtered tailings. For instance, in the base case scenario discussed in this paper, the cost to win, load, haul, spread, moisture condition, and compact low-permeability fill for constructing the starter embankment was assumed for hauling, spreading and compacting filter cake in the dry stack (AUD 3.65/t). However, consultants in WA also suggested using AUD 1/t. 


\section{$3 \quad$ Results and discussions}

\subsection{Total net present cost comparison}

The results of this work are based on the completion of NPC analyses. Comparative evaluations are based on the costs of disposing the tailings in WA as slurry, thickened, and filtered. For each option, a conceptual TSF design with associated equipment configuration and required infrastructure was developed. Capital, operating, and closure cost estimates were prepared for each alternative. A chart comparing the results of the total NPC, CAPEX, OPEX and closure costs is shown in Figure 2.

Net Present Cost @ 10\%

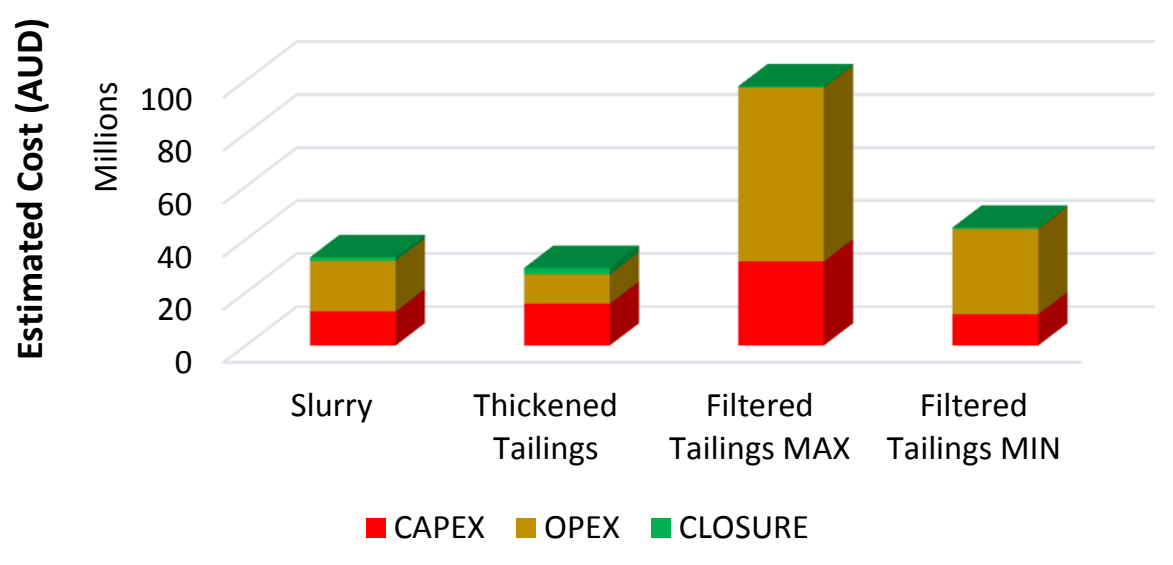

Figure 2 Comparative NPC, CAPEX, OPEX and closure costs

Overall, comparison of the estimated total NPC shows that disposing the tailings as thickened results in the lowest cost, while as filtered results in the highest cost. For this specific case study, and at the mentioned level of design detail, the estimated unit cost per dry tonne of tailings is AUD 1.11 for the slurry, AUD 0.98 for the thickened tailings, and ranges from AUD 3.26 to 1.48 for filtered tailings.

Comparison of CAPEX and OPEX also shows higher costs for the filtered tailings system, while comparison of closure costs shows higher costs for the thickened tailings option. In the base case scenario, capital investment for the filtered tailings option is more than double the required investment for each of the other options. Comparative operating costs show a big difference. The estimated OPEX of the filtered tailings alternative is 2.5 times higher than OPEX of the slurry option, and almost 5 times higher than OPEX of the thickened tailings solution. Closure costs for the thickened tailings TSF, although involving simple rehabilitation works, are $84 \%$ higher than the closure costs of the slurry option, and almost 4 times higher than the closure costs of the filtered tailings option.

\subsection{Comparative evaluation of capital cost}

The comparison of the total capital cost required for each alternative indicates that, due to the differences in dewatering technology, tailings pumping and transport systems, and disposal method, the initial investment is higher for the filtered tailings option, followed by the thickened tailings and then slurry options. A graph showing the cost comparison of the items considered in the CAPEX estimates is shown in Figure 3. 


\section{Comparative CAPEX}

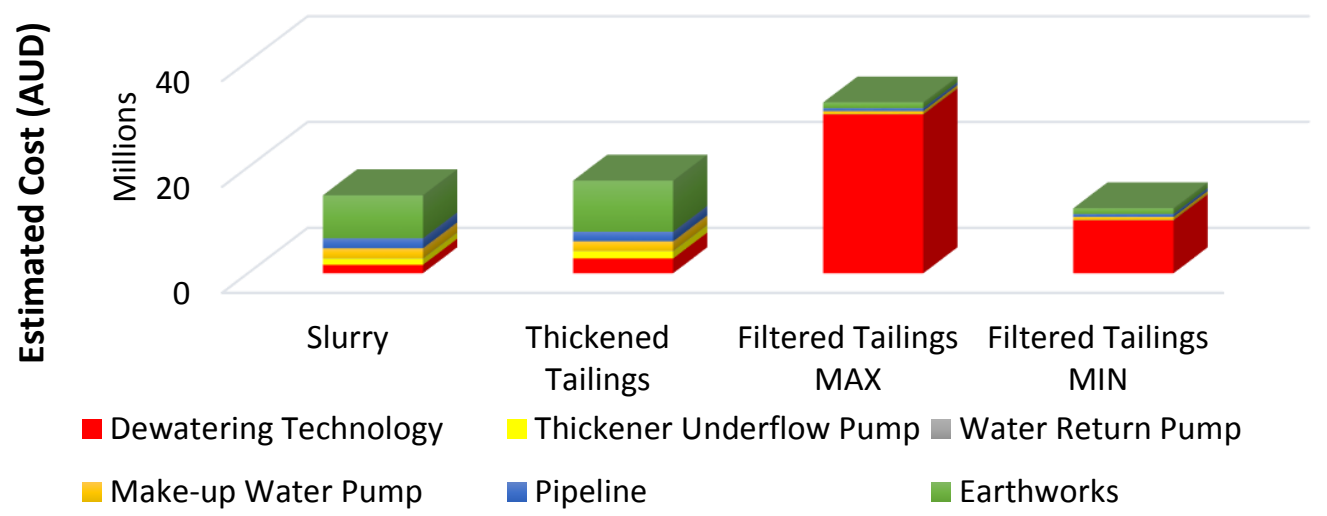

Figure 3 Comparative capital costs

For the base case scenario, as reported in the literature, the up-front capital associated with dewatering technologies to produce high-density tailings is higher. Capital investment for the supply and installation of a filtration plant is more than double the total capital cost of the slurry and thickened tailings options, including the required TSF infrastructure. However, considering a suggested cheaper capital cost (i.e. the AUD 10 M CAPEX option) for the filtration plant, which is perhaps realistic considering recent developments in filtration technologies, CAPEX of the filtered tailings would represent the cheapest one, being $9 \%$ cheaper than the CAPEX of the slurry option, and $34 \%$ cheaper than the CAPEX of the thickened tailings option.

Comparing capital investment in dewatering technology, the cost of supply and installation of a high-compression thickener is $75 \%$ more expensive than the cost of a high-rate thickener. However, there is a big difference in capital investment for the supply of thickening and filtering technologies. CAPEX of the filtration plant is more than 17 times more expensive than the CAPEX of the thickening plant for the slurry alternative, and almost 10 times more expensive than the CAPEX of the thickening plant for the thickened tailings option.

Differences in the degree of dewatering applied to the tailings is also reflected in the cost of thickener underflow pumps. Due to the difference in shear yield stress of the tailings, centrifugal pumps were selected for the slurry, and a positive displacement (PD) pump for the thickened tailings. The cost of supply and installation of one PD pump was estimated as $18 \%$ higher compared to the supply and installation of 10 centrifugal pumps. Even when considering the installation cost of centrifugal pumps as $100 \%$ of the cost of supplying them, compared to $50 \%$ considered for installing PD pumps, CAPEX of PD pumps is significantly higher. However, the short life span anticipated for the centrifugal pumps, requiring spares worth $1 / 3$ of the pump supply cost per year, escalates the operating cost of the slurry option throughout the LOM. It should be noted that some projects may require two PD pumps arranged in a duty/standby configuration, thus increasing the CAPEX of thickened tailings.

For this case study, the total capital cost is not significantly affected by the cost of supply and installation of pumps for return and make-up water. According to quotations obtained from third parties, supply costs of centrifugal water pumps do not vary significantly with relatively small differences in pumping capacity. However, it should be noted that the costs of drilling boreholes for supplying make-up water, and costs associated with fees for withdrawing groundwater were not accounted for in the estimates. These costs would ultimately affect the capital costs of the slurry option in which less volume of water is recycled in the plant. As the slurry tailings have the lowest solids content, the volume of discharged water is higher, and consequently the make-up water requirement is also higher. Even when considering the return of decant water, some is expected to be retained in the tailings, or lost through seepage and evaporation. 
CAPEX for supplying and installing a pipeline for the slurry and thickened tailings options is almost the same. However, considering that the filtered tailings option does not involve pumping tailings to the TSF for disposal, the investment in a pipeline for this solution is more than three times lower. The highest investment in a pipeline is for the slurry option because it requires an extensive slurry ring along the perimeter embankment needed for tailings discharge, and a significant number of spigots and conductor pipes to deliver tailings to the beach level.

A comparative evaluation of the NPC of earthworks for building the TSFs shows that the costs of the CTD option is the highest among the alternatives, being $19 \%$ more expensive than the slurry option, and more than eight times more expensive than the filtered tailings option. Identified key elements driving the costs of earthworks are the footprint area and the construction of embankments for tailings containment. The area to be occupied by the CTD alternative is more than three times larger than the area required for the disposal of slurry, and almost seven times larger than the area required for the filtered tailings option.

It should be noted that the difference of $19 \%$ in the costs of earthworks for the slurry and thickened tailings options is very small compared to how different the TSF designs are. A comparison of the earthwork costs of these two options, which are mainly related to topsoil stripping and construction of TSF infrastructure, reveals that site preparation for the CTD option is more than twice as expensive. However, the savings in topsoil stripping realised by the slurry option is somewhat offset by the large volume of construction material needed for building the starter embankment. The required capital cost for the construction of an embankment to contain slurry tailings is three times higher than the cost to build an embankment for containing thickened tailings. During the construction phase, the dam volume required for the slurry option was estimated to be approximately $600,000 \mathrm{~m}^{3}$, whereas the estimated total dam volume required for the thickened tailings option decreases to $127,000 \mathrm{~m}^{3}$.

On the other hand, but also driven by the large footprint area required for the CTD option, earthwork costs associated with the construction of ponds next to the TSF offset the savings realised with dam construction. Thickened tailings are considered to be non-segregating and to produce minimal bleed water. Hence, underdrainage and a decant system was not considered necessary. However, due to the vast surface area of the tailings cone, a shallow pond was designed for storm water management, and a smaller lined pond was designed for precipitation runoff management. Comparative capital costs shows that the costs of pond construction for the thickened tailings option is more than 3.5 times the costs of constructing the underdrainage and decant systems for the slurry solution. For the filtered tailings option, as the total surface area of the dry stack is much smaller than the large surface area of the cone, the costs of constructing the ponds for managing surface water are more than four times cheaper than for the CTD option.

The capital costs of the CTD option also include the construction of an access spine way to the tailings discharge point to be located in the centre of the facility. This cost represents $26 \%$ of total CAPEX associated with earthworks required for the CTD option, and is not required for the slurry or for the filtered tailings options.

\subsection{Comparative evaluation of operating costs}

Overall, in the base case scenario, a comparative evaluation of OPEX shows that operating costs are higher for the filtered tailings option, being almost 2.5 times higher than the slurry option, and almost five times higher than the thickened tailings option. A graph showing the cost comparison of the items considered in the OPEX estimates is shown in Figure 4. For this specific study, and at the mentioned level of design detail, the estimated operating cost per dry tonne of tailings is AUD 0.64 for slurry, AUD 0.37 for thickened tailings, and ranges from AUD 2.18 to 1.07 for filtered tailings. 


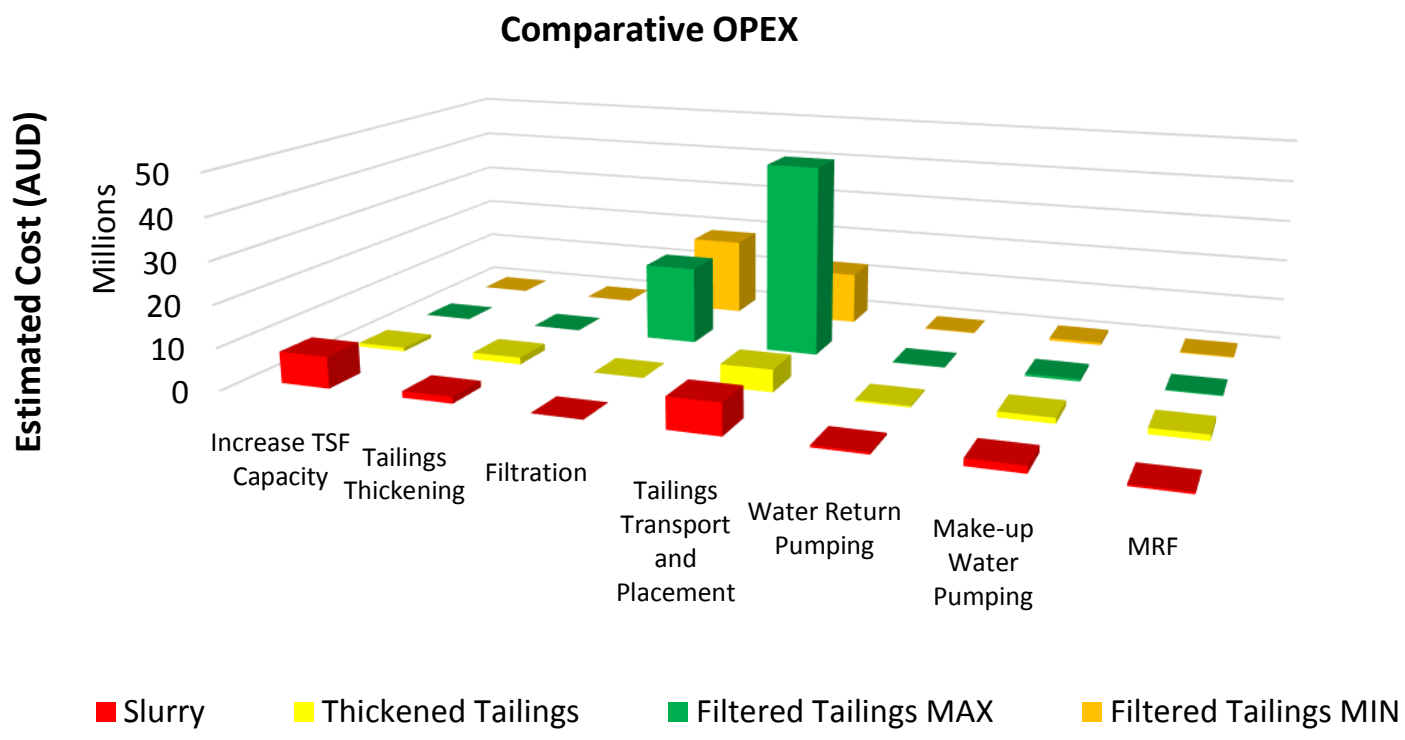

\section{Figure 4 Comparative operating costs}

High OPEX for the filtration solution is primarily due to the cost of transporting, spreading, and compacting filtered tailings. However, it should be highlighted that, as realised in this specific case study, operating costs for filtered tailings are very sensitive to the unit rate assumed for tailings transport and placement. Investigating alternative solutions for tailings transport, e.g. using dry stacking of tailings by conveyor instead of transport by truck, is crucial for estimating the costs of disposing filtered tailings. Unit rates can vary significantly, especially with the scale of the operation, distance of transport, cost of fuel, labour, etc.

Increasing the TSF capacity was considered just for the slurry and thickened tailings options, and it highlights the main difference between the two alternatives. The TSF designed for the slurry tailings considers the containment of wet tailings that require a perimeter embankment to retain slurry and decant water. The CTD option was designed considering that the thickened tailings will form a self-supporting cone requiring no containment wall. Instead, it was assumed that the construction of an environmental embankment was for water management purposes only. For this specific case study where the TSF is to be built on a flat terrain, operating costs of increasing the TSF capacity for the slurry option is significantly higher. It was estimated that the NPC for raising the dam throughout the LOM is more than eight times the NPC for raising the tailings deposition point for the CTD option.

Tailings thickening was also just considered for the slurry and thickened tailings options, but the costs do not vary significantly between the alternatives. However, operating costs of pumping tailings using five centrifugal pumps in series for the slurry alternative make it $38 \%$ more expensive than pumping thickened tailings using a PD pump. This difference in costs is given by the difference in pumping systems adopted for each option. At lower solids content, slight variations in density do not create a big difference in rheology, hence centrifugal pumps were considered for the slurry tailings. As solids content increases, the rheology becomes more sensitive to smaller variations in density - an effect that may be an issue for centrifugal pumps. PD pumps were therefore selected for the thickened tailings. In spite of having similar discharge pressures, the power consumption of the five centrifugal pumps in series is higher than the power consumption of a single PD pump, manifesting as higher OPEX for the slurry option. The costs of spares for centrifugal pumps are also higher as they have a shorter operating life. In the prepared cost estimates, OPEX incurred on pumping tailings and water include the cost of supplying pump spares. It was considered that centrifugal pumps require spares worth $1 / 3$ of the pump cost per year, whereas PD pumps require spares worth $3 \%$ of the pump cost per year.

For the filtered tailings option, operating costs associated with the filtration plant include power consumption (which is significantly higher compared to the thickening plants), and costs of spares and 
wearing parts, e.g. supply of filter cloths. These operational costs represent $28 \%$ of the total OPEX considered for the filtered tailings alternative, and are not required for the slurry or thickened tailings options.

Based on the recent context of increasing power access fees in WA, and considering a common concern about the high power consumption of filtration plants, a scenario in which electricity charges double was analysed. In this study, the estimated power consumption in kWh per dry tonne of filtered tailings is 2.65 , being $162 \%$ higher than the thickened tailings option $(1.63 \mathrm{kWh} / \mathrm{t})$ and $24 \%$ higher than the slurry option $(2.15 \mathrm{kWh} / \mathrm{t})$. In this case, the estimated operating cost per dry tonne of tailings for the slurry and thickened tailings options was found to considerably affect the operating costs of these alternatives. OPEX of the slurry option would increase by $47 \%$ (from AUD 0.64 to $0.93 / \mathrm{t}$ ), and OPEX of the thickened tailings option would increase by $61 \%$ (from AUD 0.37 to $0.59 / \mathrm{t}$ ). Although being the option with the highest power consumption, in case electricity charges double, OPEX of the filtered tailings alternative would increase by 17\%, from AUD 2.18 to 2.55 . As OPEX of this solution is mainly affected by the high cost of transporting and placing the filter cake, energy consumption was not found to significantly affect operating costs. However, in case a lower rate for transporting and placing filter cake is considered, OPEX of this option would increase 34\%, from AUD 1.07 to 1.44/t. Improving energy efficiency is, therefore, an important aspect of reducing operating costs of disposing tailings.

OPEX associated with pumping return and make-up water reflect the degree of dewatering applied to the tailings at the plant. A comparative evaluation shows that the water pumping cost of the slurry option is $25 \%$ more expensive than the thickened tailings option, and almost twice as expensive as the filtered tailings alternative. It should be noted that for this specific case study, and based on an existing TSF in WA, it is considered that $55 \%$ of water discharged with the slurry will be collected and returned to the mill for re-use. In case less water reclaim is considered from the TSF, what is decidedly possible in an arid region, even higher OPEX would be expected as a result of lower volume of recycled water as well as higher make-up water requirement.

In this specific case study, the annual cost of pumping make-up water represents $9 \%, 12 \%$ and $1 \%$ of total estimated OPEX for the slurry, thickened, and filtered tailings options, respectively. If mining operators would in future be required to pay for the use of groundwater, this cost element would significantly impact the total operating costs. A cost-benefit analysis for a case where water costs AUD $3 / \mathrm{m}^{3}$ showed that the costs associated with make-up water represent $47 \%$ of total OPEX for the slurry, $54 \%$ for the thickened tailings, and $8 \%$ for the filtered tailings options. Given threats posed by water scarcity worldwide, increasing recycled water in the plant through dewatering tailings may be required to reduce operating costs.

A comparative evaluation of the levy payable to the MRF shows that the NPC of the CTD option is more than three times the NPC of the slurry option, and more than six times the NPC of the filtered tailings option. This difference is due to the large footprint area required for the disposal of thickened tailings, the greater area occupied by the overburden stockpile, and the area disturbed by the ponds that is classified as category ' $A$ ' with the associated unit rate being the highest one.

An analysis of the rehabilitation costs of the designed TSFs in this case study was carried out to verify if an increased levy payable to the MRF would be realistic. The NSW Rehabilitation Tool suggests allowing for post-closure monitoring costs ( $5 \%$ of direct rehabilitation costs), project management and surveying costs $(10 \%)$, and contingency costs (10\%). If those costs are considered in the estimates, and allowing for a monitoring period of 20 years, the estimated rehabilitation costs would be of the order of AUD 185,000/ha for the TSF for containing slurry, AUD 46,000/ha for the thickened tailings facility, and AUD 38,000/ha for the dry stack.

Based on the rehabilitation costs realised in this case study, a scenario in which the unit rate for the area disturbed by a class one TSF increases to AUD 100,000, and the FCR rises to $1.5 \%$ was analysed. The annual levy payable to the MRF for the CTD option, which requires a vast area for tailings disposal, would represent almost $1 / 3$ of all the operating costs considered in the OPEX estimate. Regarding the significant effect the annual contribution to the MRF would have on operating costs in this case, an important point should be highlighted. As per the MRF regulations, the unit rate for land under rehabilitation decreases significantly to AUD 2,000/ha. Progressive rehabilitation may, therefore, become crucial to reduce operating costs, especially given the issues of tightening regulations discussed in this paper. 


\subsection{Comparative evaluation of closure and rehabilitation cost}

A comparative evaluation of the closure cost estimates shows that the rehabilitation costs are more expensive for the thickened tailings option. The main element driving the rehabilitation cost for the CTD option is associated with hauling and placing topsoil to cap the vast surface area of the cone. As central thickened discharge results in a relatively low-elevation tailings deposit covering a very large footprint, the required financial provisioning for a very large volume of suitable cover material makes it the most expensive TSF to be rehabilitated. For this specific case study, the NPC of rehabilitation works for the thickened tailings are of the order of AUD 2.5 M (AUD 0.08/dry t) compared to AUD $1.3 \mathrm{M}$ (AUD 0.04/dry t) for the slurry option, and AUD 0.5 M (AUD 0.02/dry t) for the filtered tailings option.

For all the options, rehabilitation works predominantly consist of hauling and placing topsoil to cap the TSF, and deep ripping and spreading seeds in all disturbed areas. Reclamation is planned to occur three years after ceasing tailings deposition for the slurry option, virtually as soon as tailings deposition ceases for the thickened tailings option, and progressively throughout the LOM for the filtered tailings option.

Comparing the slurry and thickened tailings alternatives, the area disturbed by the disposal of thickened tailings using the CTD method is more than three times the area disturbed by the slurry tailings dam. Thus it was expected that rehabilitation costs should reflect the significant difference in footprint. However, because of the difference in water content of the deposited tailings, different approaches were considered for the closure of each TSF. As the slurry option involves the disposal of relatively wet tailings, additional work for capping the facility with a layer of hard rock was costed. It is a common practice in WA aimed at reducing erosion, and impeding capillary action and the upward movement of salt within the profile. On the other hand, rehabilitation of the thickened and filtered tailings facilities generally consists of the straightforward application of topsoil placement and revegetation.

Comparative closure costs in present-day (year zero) monetary terms are AUD 14,000/ha for area disturbed by the slurry option, AUD 7,000/ha for the thickened tailings option, and AUD 9,000/ha for the filtered tailings option. It should be noted that the actual costs for rehabilitating the dry stack is the lowest, being 1.6 times cheaper than the slurry option, and almost four times cheaper than the thickened tailings option. However, as mentioned before, discounting procedures used to calculate the present value of project alternatives favour the options where costs can be deferred. As estimated closure costs for the slurry and thickened tailings facilities occur far in the future, costs are virtually small in present-day terms if compared to closure costs of the dry stack that occur throughout the LOM.

In a scenario, which is perhaps more realistic and in some ways realised by some mining projects, in which at the time of closure the rehabilitation cost increases three times the initial estimate, the total NPC would increase by $8 \%, 17 \%$ and $1 \%$ for the slurry, thickened, and filtered tailings options, respectively. In this case, the large footprint required for tailings management results in a significant increase in the total cost of tailings disposal. This would ultimately affect the finances of the project, especially at the end of the LOM, when revenue from mining operations is not expected.

It should be noted that the lifecycle considered for discounting the rehabilitation costs is different due to the differences in tailings solids content. A period of three years drying is allowed for the slurry TSF, so that heavy earth moving equipment can begin placing cover layers. Then, after rehabilitation works are completed, a period of three years waiting for regulator approval was allowed for. Monitoring costs are accounted for in the estimates for this period of three years, and for the following 10 years of post-closure monitoring. For the thickened and filtered tailings options, after performing final rehabilitation works, monitoring costs are considered for one year for regulator approval, and for the following 10 years of post-closure monitoring.

\section{Conclusion}

Increasingly stringent regulatory requirements for the disposal of mine waste and changing public expectations will intensify the pressure on the mining industry to become more sustainable. The continuous growth of the industry depends on having a strong commitment to the development of technology that offer 
opportunities to mitigate the environmental impacts of tailings disposal, lower the risk of catastrophic TSF failures, reduce water use, and produce stable landforms at closure. When evaluating project options, it is important to recognise that the attractiveness of reducing costs in the short-term must be carefully weighed against the possibility of increasing environmental, social, and risk costs throughout the LOM and beyond.

A conclusion to be drawn from this case study is that disposing the tailings using filtration technology resulted in the highest NPC when compared to the thickening technologies. However, some key elements driving the costs of tailings disposal are related to the storage of low-density slurries, e.g. high costs associated with the large footprint required for tailings storage, the high volume of construction material required for building retaining embankments, the high volume of make-up water needed for mineral processing, and the complex work to rehabilitate the site at closure. It should be highlighted that these elements directly affect mine sustainability performance and tailings production costs. There are a number of uncertainties and potential sources of variability of these elements, and it can tip the balance in favour of the disposal of filtered tailings.

As discussed in this paper, the current evaluation methodologies used to decide on the preferred method for the disposal of tailings rely on a narrow set of parameters for cost estimation, and may no longer point to the most cost-effective option. Using dewatered tailings is often deemed undesirable because of economics. This conclusion has sometimes resulted from evaluations that do not incorporate all the costs that may potentially affect the finances of a project. Furthermore, the lack of publically available information on the cost of tailings management generally poses a challenge to future tailings strategy decision-making.

In the context of the aforementioned issues, identifying the elements driving the costs of disposing tailings is part of ongoing research aimed at addressing the long-standing challenges of quantifying the benefits and external costs of alternative methods for surface tailings disposal. They are difficult to incorporate in cost estimates, but may significantly affect the environmental, social, and financial sustainability of a project. In the lead-up to the selection of a tailings disposal option, the environmental and social impacts of each alternative's lifecycle should be characterised, and a financial value assigned to them. Risk costs should also be included, possibly by quantifying the clean-up and repair costs incurred from the failure of projects with similar characteristics.

Therefore, a tailings disposal method should be selected based on the assessment of the accumulated costs, using an integrated approach. In the future, the benefits of high-density tailings storage will become more prominent, particularly as external pressures force mining operators to seek alternative strategies for tailings disposal. In this context, there is an ongoing need to adopt more holistic methodologies for comparative evaluations, and to research the lifecycle costs of different management strategies. This provides decision-makers with a tool to pursue appropriate and sustainable tailings solutions.

\section{References}

Business Queensland, Queensland Government 2017, Mining Financial Assurance Calculator, viewed 15 February 2018 , https://www.business.qld.gov.au/running-business/environment/licences-permits/rehabilitation/security-deposit

Carneiro, A \& Fourie, AB 2017, 'Economic evaluation for the disposal of slurry versus thickened tailings in Western Australia - A case study', in GW Wilson, DC Sego and NA Beier (eds), Proceedings of the Twenty-first International Conference on Tailings and Mine Waste, University of Alberta Geotechnical Centre, Edmonton, pp. 138-149.

Espinoza, RD \& Morris, JWF 2016, 'Towards sustainable mining (part II): accounting for mine reclamation and post reclamation care liabilities', https://doi.org/10.13140/rg.2.1.3188.6966

Fitton, TG \& Roshdieh, A 2013, 'Filtered tailings versus thickened slurry: four case studies', in RJ Jewell, AB Fourie, J Caldwell and J Pimenta (eds), Proceedings of the 16th International Seminar on Paste and Thickened Tailings, Australian Centre for Geomechanics, Perth, pp. 275-288.

Johnson, D, Moghaddam, R, Bin Ahmed, I \& Laroche, C 2013, 'Comparative evaluation of surface disposal of thickened versus slurry tailings', in RJ Jewell, AB Fourie, J Caldwell and J Pimenta (eds), Proceedings of the 16th International Seminar on Paste and Thickened Tailings, Australian Centre for Geomechanics, Perth, pp. 289-302.

Klohn Crippen Berger 2017, Study of Tailings Management Technologies, viewed 10 November 2017, http://mend-nedem.org/wpcontent/uploads/2.50.1Tailings_Management_TechnologiesL.pdf

State of New South Wales and Department of Planning and Environment, 2017 Rehabilitation Cost Estimation Tool, viewed 1 February 2018, http://www.resourcesandenergy.nsw.gov.au/miners-and-explorers/rules-and-forms/pgf/environmental-guidelines

The Australasian Institute of Mining and Metallurgy 2012, Cost Estimation Handbook, 2nd edn, Monograph 27, The Australasian Institute of Mining and Metallurgy, Melbourne. 